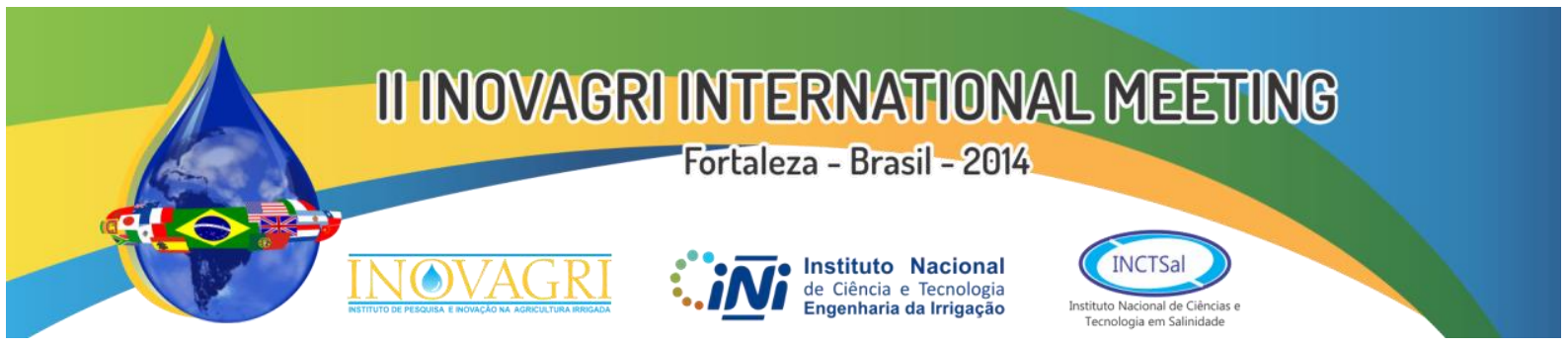

http://dx.doi.org/10.12702/ii.inovagri.2014-a166

\title{
EFEITO DE DOSES DE GESSO SOBRE O CRESCIMENTO DE GENÓTIPOS DE MAMONEIRA EM SOLO SALINO-SÓDICO
}

\author{
J. P. Alexandre ${ }^{1}$, J. H. Zonta ${ }^{2}$, E. S. A. B. de Almeida ${ }^{3}$, W. P. Araújo ${ }^{4}$, V. Sofiatti ${ }^{2}$, J. R. Pereira ${ }^{5}$
}

RESUMO: Com o objetivo de verificar o efeito de diferentes doses de gesso no crescimento inicial de genótipos de mamoneira sobre solo salino-sódico, um ensaio experimento foi conduzido em casa de vegetação, localizada na Embrapa Algodão, no município de Campina Grande, PB. Foi coletado solo salino-sódico, proveniente da região de Ipanguaçu, RN. O experimento foi instalado num esquema fatorial $4 \times 4$, sendo os tratamentos constituídos por 4 doses de gesso agrícola $(0 \% \mathrm{NG}, 50 \% \mathrm{NG}, 100 \% \mathrm{NG}$, e $150 \%$ NG) e 4 genótipos de mamoneira (BRS Energia, BRS Paraguaçu, BRS Gabriela e CNPAM 2009-7), distribuídos em delineamento experimental inteiramente ao acaso com 4 repetições. $\mathrm{O}$ solo, depois de corrigido sua fertilidade e aplicado o gesso em função dos tratamentos, foi colocado em baldes com volume de 10 litros. Aos 60 dias após a emergência foram feitas avaliações do crescimento das plantas por meio da altura das plantas, diâmetro caulinar e área foliar. Observou-se que o diâmetro do caule e a altura de planta foram influenciados pelas doses de gesso. As cultivares de mamoneira não foram afetadas pelas doses de gesso em todas as variáveis analisadas. Quanto à interação entre cultivares x gesso, apenas a variável altura de planta foi influenciadas. Podemos concluir que as doses de gesso influenciaram o crescimento inicial da mamoneira.

PALAVRAS CHAVE: Ricinus communis L., altura, diâmetro, área foliar

\section{EFFECT OF DOSES OF PLASTER ON GROWTH OF YIELD IN CASTOR SALINE-SODIC SOIL}

ABSTRACT: In order to verify the effect of different doses of gypsum on the growth of castor bean genotypes on saline-sodic soil, a trial experiment was conducted in a greenhouse at Embrapa Cotton located in the city of Campina Grande, PB. Was collected saline-sodic soil, from the region of Ipanguaçu, $\mathrm{RN}$. The experiment was a $4 \times 4$ factorial, with treatments consisting of 4 doses of gypsum $(0 \% \mathrm{NG}$, $50 \% \mathrm{NG}, 100 \% \mathrm{NG}$ and $150 \% \mathrm{NG}$ ) and 4 genotypes of castor bean (BRS Energy, BRS Paraguassu, BRS Gabriela and CNPAM 2009-7), distributed in completely randomized experimental design with four replications. The soil after corrected fertility and the plaster applied on the treatments was placed in buckets with a volume of 10 liters. At 60 days after emergence were evaluated plant growth by plant height, stem diameter and leaf area. It was observed that the stem diameter and plant height were influenced by rates of gypsum. The castor bean were not affected by rates of gypsum in all variables. Regarding the interaction between cultivars $\mathrm{x}$ gypsum, only plant height was influenced. We conclude that the rates of gypsum influenced the early growth of castor bean.

KEYWORDS: Ricinus communis L., height, diameter, leaf area

\footnotetext{
${ }^{1}$ Graduando em Agronomia. UFPB/CCA. Areia - Paraíba. Email: jpagroalexandre@ hotmail.com.

2 Doutor. Pesquisador da Embrapa Algodão. Campina Grande - Paraíba. Email: joao-henrique.zonta@embrapa.br; valdinei.sofiatti@embrapa.br.

${ }^{3}$ Engenheira Agrônoma. Estagiária da Embrapa Algodão. Campina Grande - Paraíba. Email: ericasamara@ gmail.com.

${ }^{4}$ Doutorando, UAEAg/CTRN/UFCG. Campina Grande - Paraíba. Email: wpacordao@ hotmail.com.

5 Doutorando, UAEAg/CTRN/UFCG. Pesquisador da Embrapa Algodão. Campina Grande - Paraíba. Email: jose.r.pereira@embrapa.br.
}

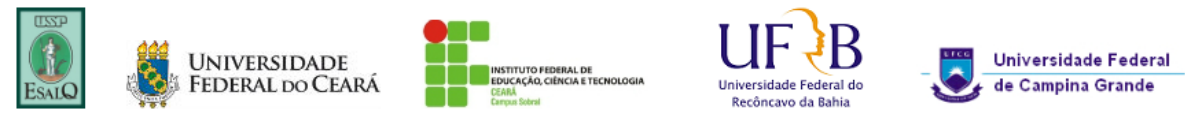




\section{INTRODUÇÃO}

A mamoneira (Ricinuscommunis L.) é uma planta de origem africana que se encontra amplamente distribuída em todo o território brasileiro, onde se adaptou com grande facilidade. Sua capacidade de adaptação a variadas condições e sua resistência ao estresse hídrico, permitem-na desenvolver-se em solos pouco férteis e em condições adversas (SEVERINO et al., 2005b). Dessa forma, amamoneira(RicinuscommunisL.)torna-seuma das oleaginosasmais importantes nocenárioeconômicodo semiárido.

A área de insuficiência hídrica do Nordeste brasileiro abrange uma superfície de 150 milhões de hectares. Nessa região, a maioria dos perímetros de irrigação apresenta solos com alto teor de salinidade, que provocam desde a diminuição nos rendimentos das culturas até o abandono das áreas exploradas (ANDRÉO-SOUZA et al., 2010).

Nas regiões áridas e semiáridas, o excesso de sais no solo tem limitado a produção agrícola, pois a salinidade, tanto dos solos como das águas, é uma das principais causas da redução do rendimento das culturas. Entretanto, os efeitos dependem, ainda, de outros fatores, como espécie, cultivar, estádio fenológico, tipos de sais, intensidade e duração do estresse salino, manejo cultural e da irrigação e condições edafoclimáticas (TESTER e DAVÉNPORT, 2003).

Uma das formas de amenizar o efeito negativo da salinidade é o uso de gesso agrícola (BERNARDO et al., 2008). Entretanto, devido principalmente ao custo com frete, muitas vezes tornase muito oneroso a aplicação do produto nas áreas, quando este é requerido em grandes quantidades.

Com relação à tolerância de diferentes genótipos de uma mesma cultura à salinidade, Galvão et al. (1998), estudando a influência de níveis de salinidade do solo em genótipos de gergelim, afirmaram que existe variabilidade entre os genótipos de gergelim em termos de tolerância à salinidade. Jácome et al. (2003) também observaram diferença quanto a tolerância à salinidade entre diferentes genótipos de algodão. Silva et al. (2008) comparando a tolerância a salinidade entre duas cultivares de mamoneira, concluíram que a cultivar BRS Energia foi mais tolerante à salinidade que a Paraguaçu, sendo mais precoce na colheita, proporcionando maior número de frutos.

Diante do exposto, objetivou-se, com o presente trabalho, verificar o efeito de diferentes doses de gesso no crescimento inicial de genótipos de mamoneira sobre solo salino-sódico.

\section{MATERIAL E MÉTODOS}

O experimento foi conduzido em casa de vegetação, localizada na Embrapa Algodão, no município de Campina Grande, PB. Foi coletado solo salino-sódico, proveniente da região de Ipanguaçu, Ceará.

O solo foi destorroado e passado em peneira de $2 \mathrm{~mm}$, sendo amostras coletadas para envio ao laboratório de Irrigação e Salinidade (LIS) da Universidade Federal de Campina Grande (UFCG) para determinação da salinidade do solo, sendo o resultado da análise apresentado na Tabela 1.

Com os resultados da análise de solo, foi determinada, de acordo com Cavalcanti (1998), a quantidade de gesso necessário para corrigir a salinidade do solo, e desta forma, determinados os tratamentos conforme a Tabela 2.

Conforme apresentado na Tabela 2, o experimento foi instalado num esquema fatorial $4 \times 4$, sendo os tratamentos constituídos por 4 doses de gesso agrícola $(0 \%, 50 \% \mathrm{NG}, 100 \% \mathrm{NG}$, e $150 \% \mathrm{NG})$ e 4 genótipos de mamoneira (BRS Energia,BRS Paraguaçu, BRS Gabriela e CNPAM 2009-7), distribuídos em delineamento experimental inteiramente ao acaso com 4 repetições.

$\mathrm{O}$ solo, depois de corrigido sua fertilidade e aplicado o gesso em função dos tratamentos, foi colocado em baldes com volume de 10 litros. Os baldes foram preenchidos 10 dias antes do plantio, sendo irrigados diariamente a fim de garantir que o gesso reaja no solo.

Após este período, no dia 21/01/2013 foram semeadas 8 sementes de mamona por vaso, a uma profundidade de 3,0 cm. Após a germinação, de três a cinco dias após a emergência das plântulas foi feito o desbaste deixando-se apenas uma planta por unidade experimental. As irrigações para manutenção da umidade dos vasos foi feita diariamente, dependendo da necessidade, sempre à 
superfície dos recipientes, por meio de microaspersores através de um sistema automatizado, com acionamento pré-programado por um "Timer".

Aos 60 dias após a emergência foram feitas avaliações do crescimento das plantas por meio da altura das plantas, diâmetro caulinar e área foliar, seguindo metodologia proposta porSeverino et al. (2005a).Foideterminada também a massa fresca e seca da parte aérea. A massa fresca da parte aérea foi determinada com uso de balança de precisão. $\mathrm{O}$ material vegetal foi seco em estufa de ventilação forçada de ar (Biopar / modelo TLK 48), a $70^{\circ} \mathrm{C}$ até peso constante. Em seguida foi pesado em balança semi-analítica (Marte Slim / modelo M2K), para determinação da massa seca da parte aérea.

Os dados obtidos foram submetidos à análise de variância e regressão.

\section{RESULTADOS E DISCUSSÃO}

Na Tabela 3 são apresentados os valores da analise de variâncias referentes aos parâmetros de crescimento inicial das cultivares de mamoneira em função das diferentes doses de gesso aplicadas ao solo.

Observa-se na Tabela 3 que para o parâmetro altura de plantas houve interação significativa, enquanto que o diâmetro do caule, massa fresca e seca da parte aérea foi influenciada somente pelas doses de gesso. A área foliar não foi influenciada nem pelas diferentes cultivares de mamoneira nem pelas doses de gesso aplicadas.

Na Figura 1 é apresentado o gráfico que relaciona o comportamento da altura das plantas de diferentes genótipos de mamoneira em função das diferentes doses de gesso aplicadas ao solo.

De acordo com a Figura 1 observa-se que a altura de plantas para as cultivares BRS Energia e BRS Gabriela apresentaram comportamento linear em função das doses de gesso, a BRS Paraguaçu apresentou comportamento quadrático, enquanto que a BRS 2009-7 não apresentou diferença para este parâmetro em função das diferentes doses de gesso.

Para a cultivar BRS Gabriela, a dose de 28,5 ton ha $^{-1}$ (150\% da necessidade de gesso) foi a que apresentou melhores resultados. Para a cultivar BRS Energia a dose 9,45 ton ha ${ }^{-1}$ (50\% da necessidade de gesso) foi a que apresentou melhores resultados e para a BRS Paraguaçu a testemunha (sem aplicação de gesso) e a dose de $150 \%$ da necessidade de gesso apresentaram os melhores resultados.

Na Figura 2, 3 e 4 é apresentado o gráfico que relacionam os valores do diâmetro do caule, massa fresca e massa seca da parte aérea da mamoneira com as doses de gesso aplicadas ao solo.

Para o parâmetro diâmetro do caule, massa fresca e massa seca da parte aérea (Figuras 2, 3 e 4) o melhor resultado foi obtido para a testemunha, ou seja, sem a adição de gesso. Esse resultado pode ser explicado se forem observados os parâmetros químicos do solo, realizado após o término do experimento. Notou-se que o teor de sódio na solução do solo aumentou com as maiores doses de gesso, devido principalmente a não lixiviação do mesmo (Figura 5).

Os teores de sódio, ao contrário do esperado, apresentaram acréscimo com o aumento das doses de gesso. Estes resultados podem ser explicados pelo fato do solo não ter sofrido lixiviação, visto que a irrigação era realizada somente com o intuito de repor a evapotranspiração diária. Segundo Leite et al. (2007), com a solubilização do gesso o teor de cálcio solúvel vai aos poucos aumentando na solução do solo, e, o cálcio reage com o sódio dos pontos de troca e o desloca da forma trocável para a forma solúvel na solução do solo, contribuindo para sua lixiviação, o que neste caso, não ocorreu. Vital et al. (2005) também encontraram elevação nos valores de sódio (Na) trocável na solução do solo com a aplicação de doses de gesso maiores que $100 \%$ da necessidade, atribuindo os resultados a uma substituição maior do Na trocável do solo pelo Ca derivado do gesso aplicado como corretivo.Devido à toxicidade do sódio devido à alta salinidade imposta pelo mesmo, as plantas apresentaram menor crescimento.

Com os resultados, observa-se que a cultivar BRS Gabriela apresenta potencial para crescimento inicial em altura mesmo com altos teores de sódio no solo, podendo ser uma cultivar em potencial para ser explorada em recuperação de solos salino-sódicos, visto seu maior desenvolvimento inicial em comparação as demais cultivares. 


\section{CONCLUSÕES}

As doses de gesso influenciaram o crescimento inicial dos genótipos de mamoneira e, para que se obtenham boas respostas do gesso no solo para correção da salinidade, é necessário que seja aplicada uma lamina de lixiviação, a fim de retirar o sódio do solo.

\section{REFERÊNCIAS BIBLIOGRÁFICAS}

ANDRÉO-SOUZA, Y.; PEREIRA, A. L.; SILVA, F. F. S.; RIEBEIRO-REIS5, R. C.; EVANGELISTA, M. R.V.; CASTRO, R. D. ; DANTAS B. F. Efeito da salinidade na germinação de sementes e no crescimento inicial de mudas de pinhão-manso. Revista Brasileira de Sementes, vol. 32, n. 2, p. 83-92, 2010. http://dx.doi.org/10.1590/S0101-31222010000200010

BERNARDO, S. ; SOARES, A. A. ; MANTOVANI, E. C. Manual de Irrigação. 8 ed. Viçosa: UFV, 2008. 596p.

CAVALCANTI, F. J. A. C. (Coord.). Recomendação de adubação para o Estado de Pernambuco. $2^{\text {a }}$ aproximação. Recife: IPA, 1998. 198p.

GALVÃO, F. de A. D.; DANTAS, J. P.; NASCIMENTO, J. S. do; ALVES, A. G. C. Influência da salinidade do solo sobre o crescimento e o estado nutricional do gergelim (Sesamum indicum L.). Agropecuária Técnica, v.19, n.1/2, p.23-29, 1998.

JÁCOME, A. G.; OLIVEIRA, R. H. de; FERNANDES, P. D.; GHEYI, H. R.; SOUZA, A. P. de; GONÇALVES, A. C. A. Crescimento de genótipos de algodoeiro em função da salinidade da água de irrigação. Acta ScientiarumAgronomy, v.25, n.2, p.305-313, 2003.

LEITE, E. M.; CAVAlCANTE, L. F.; DINIZ, A. A.; SANTOS, R. V.; ALVES, G. S.; CAVALCANTE, I. H. L. Correção da sodicidade de dois solos irrigados em resposta à aplicação de gesso agrícola. Irriga, v.12, n.2, p.168-176, 2007.

SILVA, S. M. S.; ALVES, A. N.; GHEYI, H. R.; BELTRÃO, N. E. de M.; SEVERINO, L. S.; SOARES, F. A. L. Desenvolvimento e produção de duas cultivares de mamoneira sob estresse salino. Desenvolvimento e produção de duas cultivares de mamoneira sob estresse salino. Revista Brasileira de Engenharia Agrícola e Ambiental, v.12, n.4, p.335-342, 2008. http://dx.doi.org/10.1590/S1415-43662008000400001

SEVERINO, L. S.; CARDOSO, G. D.; VALE, L. S. do; SANTOS, J. W. dos. Método para determinação da área foliar da mamoneira. Campina Grande: Embrapa Algodão, 2005a. 20 p. (Embrapa Algodão. Boletim de Pesquisa e Desenvolvimento, 55).

SEVERINO, L. S.; LIMA, C. L. D.; BELTRÃO, N. E. M.; CARDOSO, G. D.; FARIAS, V. A. Comportamento da mamoneira sob encharcamento do solo. Campina Grande: Embrapa Algodão, 2005b. 16 p. (Embrapa Algodão. Boletim de Pesquisa e Desenvolvimento, 57).

TESTER, M.; DAVÉNPORT, R. Na+tolerance and Na+transport in higher plants. AnnalsofBotany, v.19, p.503-527, 2003.

VITAL, A. F. M.; SANTOS, R. V.; CAVAlCANTE, L. F.; SOUTO, J. S. Comportamento de atributos químicos de um solo salino-sódico tratado com gesso e fósforo. Revista Brasileira de Engenharia Agrícola e Ambiental, v.9, n.1, p.30-36, 2005. http://dx.doi.org/10.1590/S1415$\underline{43662005000100005}$ 
Tabela 1. Análise do solo utilizado no experimento. Campina Grande, PB, 2013.

\begin{tabular}{lc}
\hline Características Químicas & Resultado \\
\hline Cálcio (meq/100 g de solo) & 20,00 \\
Magnésio (meq/100 g de solo) & 15,30 \\
Sódio (meq/100 g de solo) & 15,62 \\
Potássio (meq/100 g de solo) & 0,35 \\
Enxofre (meq/100 g de solo) & 51,27 \\
Hidrogênio (meq/100 g de solo) & 3,31 \\
Alumínio (meq/100 g de solo) & 0,20 \\
T (meq/100 g de solo) & 54,78 \\
Carbonato de cálcio Qualitativo (\%) & Ausência \\
Carbono Orgânico (\%) & 0,59 \\
Matéria Orgânica (\%) & 1,02 \\
Nitrogênio (\%) & 0,05 \\
Fósforo Assimilável (mg/100ml) & 5,35 \\
pH H2O (1:2,5) & 5,26 \\
pHKCl (1:2,5) & \\
Cond. Elétrica (mmhos/cm) (Suspensão solo-água) & 8,707 \\
pH (Extrato de Saturação) & 4,96 \\
Cond. Elétrica (mmhos/cm)(Extrato de Saturação) & 24,87 \\
Cloreto (meq/l) & 245,00 \\
Carbonato (meq/l) & 0,00 \\
Bicarbonato (meq/l) & 2,50 \\
Sulfato (meq/l) & Presença \\
Cálcio (meq/l) & 77,00 \\
Magnésio (meq/l) & 93,50 \\
Potássio (meq/l) & 0,47 \\
Sódio (meq/l) & 91,98 \\
Percentagem de saturação & 60,00 \\
Relação de adsorção de sódio & 9,96 \\
PST & 28,51 \\
Salinidade & Muito forte \\
Classe do solo & Salino Sódico \\
\hline & \\
& \\
&
\end{tabular}

Tabela 2. Tratamentos utilizados no ensaio experimental. Campina Grande, PB, 2013.

\begin{tabular}{|c|c|c|c|}
\hline TRATAMENTO & DOSE DE GESSO & CULTIVAR & $\begin{array}{l}\text { Dose de gesso } \\
\text { (gramas/balde) }\end{array}$ \\
\hline 1 & $0 \%$ & BRS Gabriela & 0 \\
\hline 2 & $0 \%$ & BRS Energia & 0 \\
\hline 3 & $0 \%$ & CNPAM 2009-7 & 0 \\
\hline 4 & $0 \%$ & BRS Paraguaçu & 0 \\
\hline 5 & $50 \%\left(9,45\right.$ ton $\left.\mathrm{ha}^{-1}\right)$ & BRS Gabriela & 63 \\
\hline 6 & $50 \%\left(9,45\right.$ ton $\left.\mathrm{ha}^{-1}\right)$ & BRS Energia & 63 \\
\hline 7 & $50 \%\left(9,45\right.$ ton $\left.\mathrm{ha}^{-1}\right)$ & CNPAM 2009-7 & 63 \\
\hline 8 & $50 \%\left(9,45\right.$ ton $\left.h^{-1}\right)$ & BRS Paraguaçu & 63 \\
\hline 9 & $100 \%\left(18,9\right.$ ton $\left.\mathrm{ha}^{-1}\right)$ & BRS Gabriela & 126 \\
\hline 10 & $100 \%\left(18,9\right.$ ton $\left.\mathrm{ha}^{-1}\right)$ & BRS Energia & 126 \\
\hline 11 & $100 \%\left(18,9\right.$ ton $\left.\mathrm{ha}^{-1}\right)$ & CNPAM 2009-7 & 126 \\
\hline 12 & $100 \%\left(18,9\right.$ ton $\left.\mathrm{ha}^{-1}\right)$ & BRS Paraguaçu & 126 \\
\hline 13 & $150 \%\left(28,35\right.$ ton $\left.\mathrm{ha}^{-1}\right)$ & BRS Gabriela & 189 \\
\hline 14 & $150 \%\left(28,35\right.$ ton $\left.\mathrm{ha}^{-1}\right)$ & BRS Energia & 189 \\
\hline 15 & $150 \%\left(28,35\right.$ ton $\left.\mathrm{ha}^{-1}\right)$ & CNPAM 2009-7 & 189 \\
\hline 16 & $150 \%\left(28,35\right.$ ton $\left.\mathrm{ha}^{-1}\right)$ & BRS Paraguaçu & 189 \\
\hline
\end{tabular}




\section{J. P. Alexandre et al.}

Tabela 3. Resumo da análise de variância (quadrados médios) referente aos dados da análise dos fatores de crescimento das plantas de mamona: altura de planta, diâmetro do caule, área foliar, massa fresca da parte aérea e massa seca da parte aérea. Campina Grande, PB, 2013.

\begin{tabular}{ccccccc}
\hline Fonte de variação & GL & $\begin{array}{c}\text { Altura de } \\
\text { planta }\end{array}$ & $\begin{array}{c}\text { Diâmetro } \\
\text { do caule }\end{array}$ & $\begin{array}{c}\text { Área } \\
\text { Foliar }\end{array}$ & $\begin{array}{c}\text { Massa } \\
\text { fresca da } \\
\text { parte aérea }\end{array}$ & $\begin{array}{c}\text { Massa seca } \\
\text { da parte } \\
\text { aérea }\end{array}$ \\
\hline Gesso & 3 & $136,2^{*}$ & $2,64^{*}$ & $374,3^{\text {ns }}$ & $310,9^{*}$ & $5,58^{*}$ \\
Cultivar & 3 & $27,3^{\text {ns }}$ & $2,01^{\text {ns }}$ & $274,3^{\text {ns }}$ & $88,75^{\text {ns }}$ & $2,16^{\text {ns }}$ \\
Cultivar x Gesso & 9 & $29,4^{*}$ & $1,46^{\text {ns }}$ & $256,3^{\text {ns }}$ & $108,8^{\text {ns }}$ & $3,29^{\text {ns }}$ \\
Resíduo & 48 & 12,6 & 0,86 & 326,5 & 85,8 & 2,2 \\
\hline Total & 63 & & & & \\
\hline
\end{tabular}

- Significativo a $5 \%$ de probabilidade; ${ }^{\text {ns }}$ - não significativo a 5\% de probabilidade.

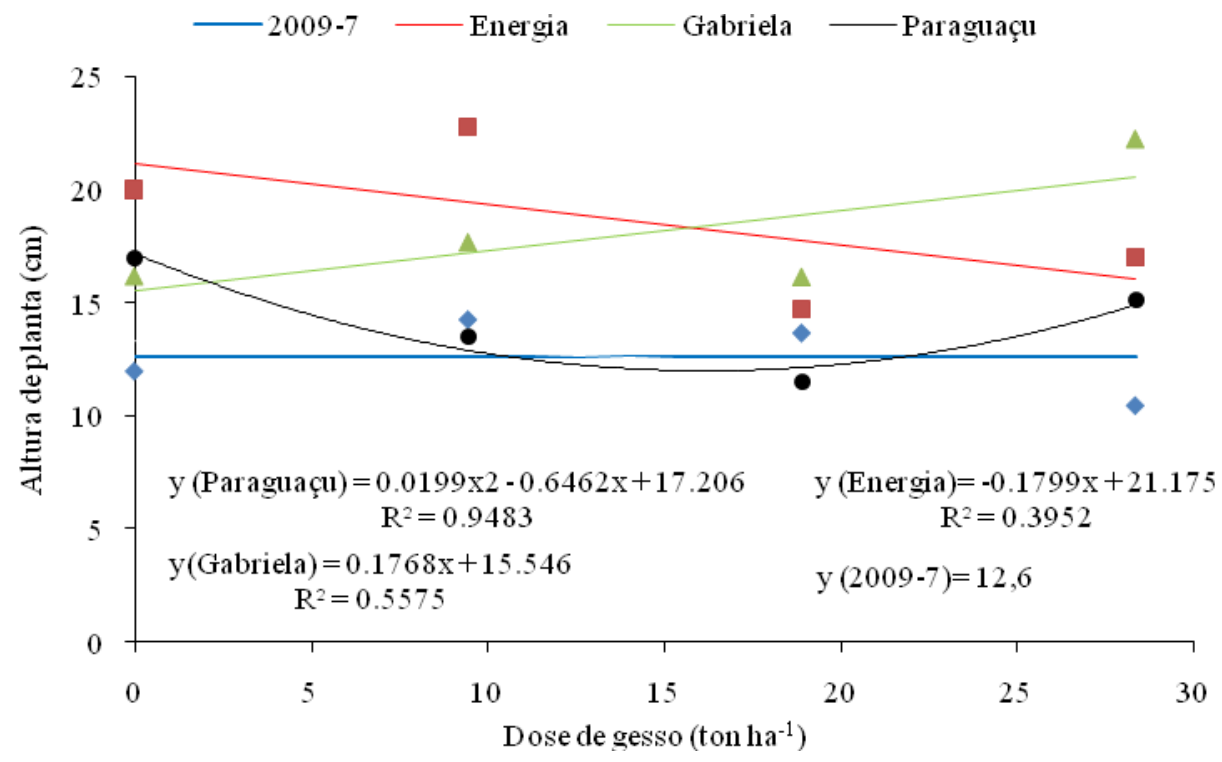

Figura 1. Altura de planta das cultivares de mamoneira em função da dose de gesso aplicada ao solo. Campina Grande, PB, 2013.

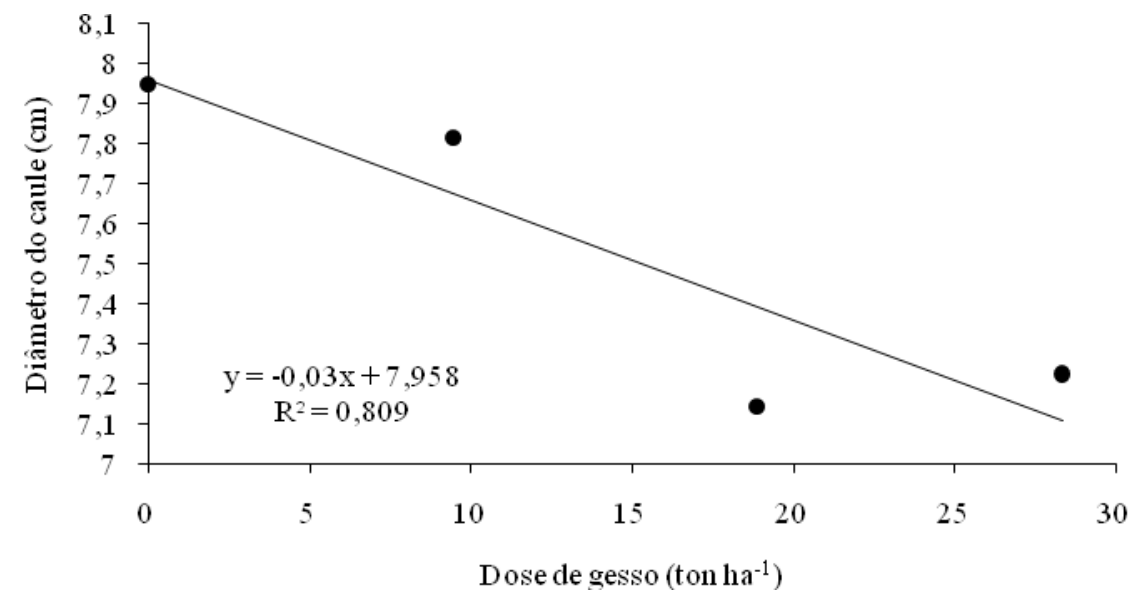

Figura 2. Diâmetro do caule da mamoneira em função de diferentes doses de gesso aplicadas ao solo. Campina Grande, PB, 2013. 


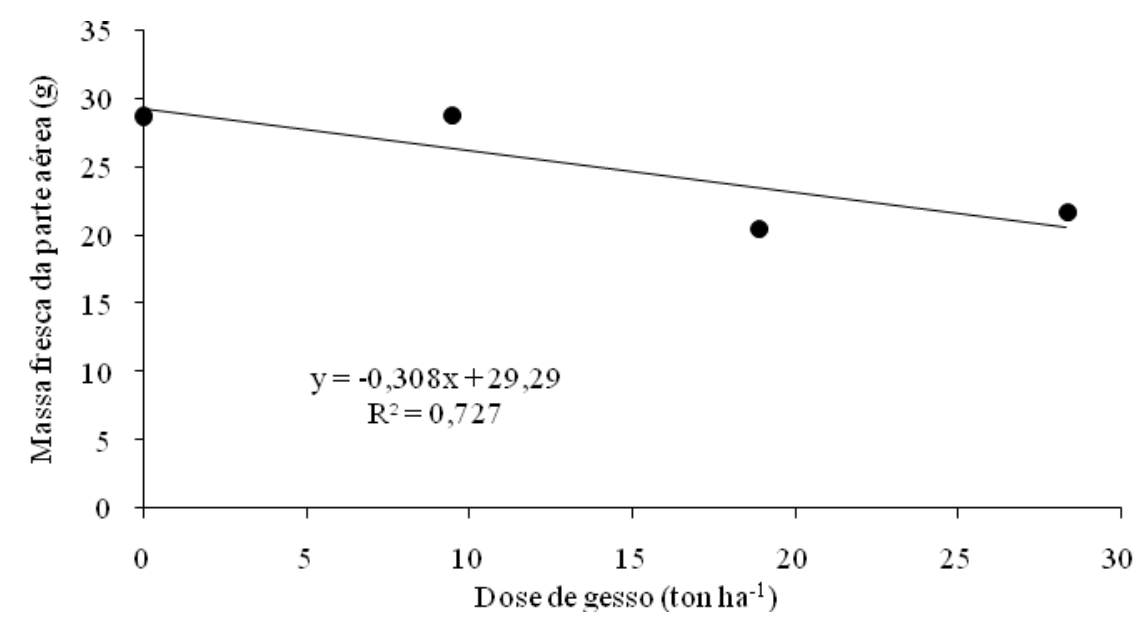

Figura 3. Massa fresca da parte aérea da mamoneira em função de diferentes doses de gesso aplicadas ao solo. Campina Grande, PB, 2013.

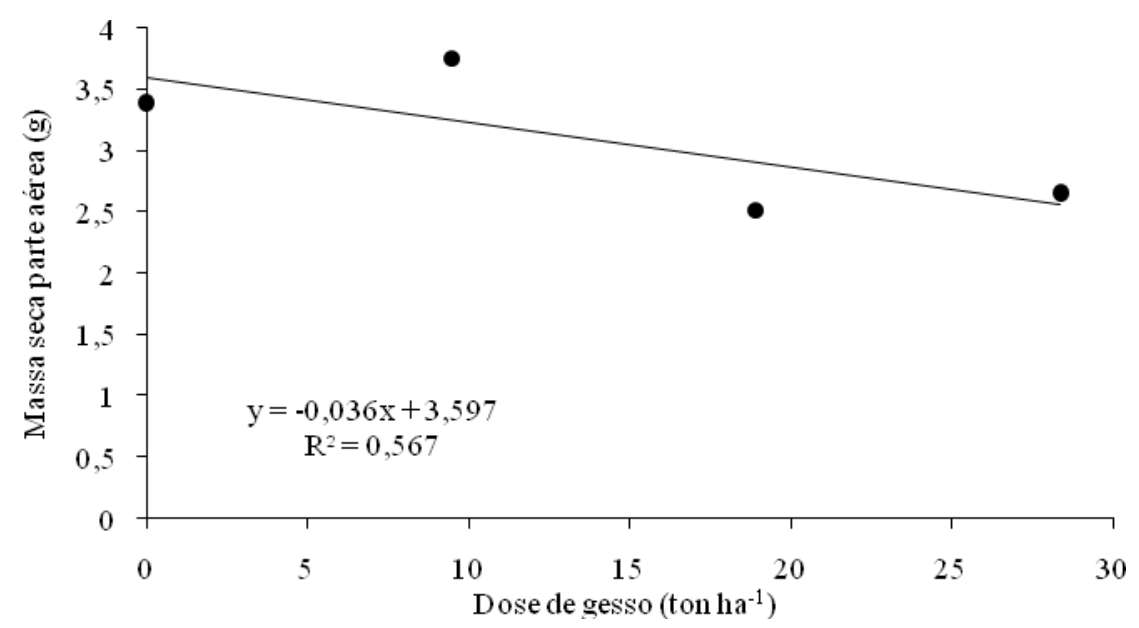

Figura 4. Massa seca da parte aérea da mamoneira em função de diferentes doses de gesso aplicadas ao solo. Campina Grande, PB, 2013. 
J. P. Alexandre et al.

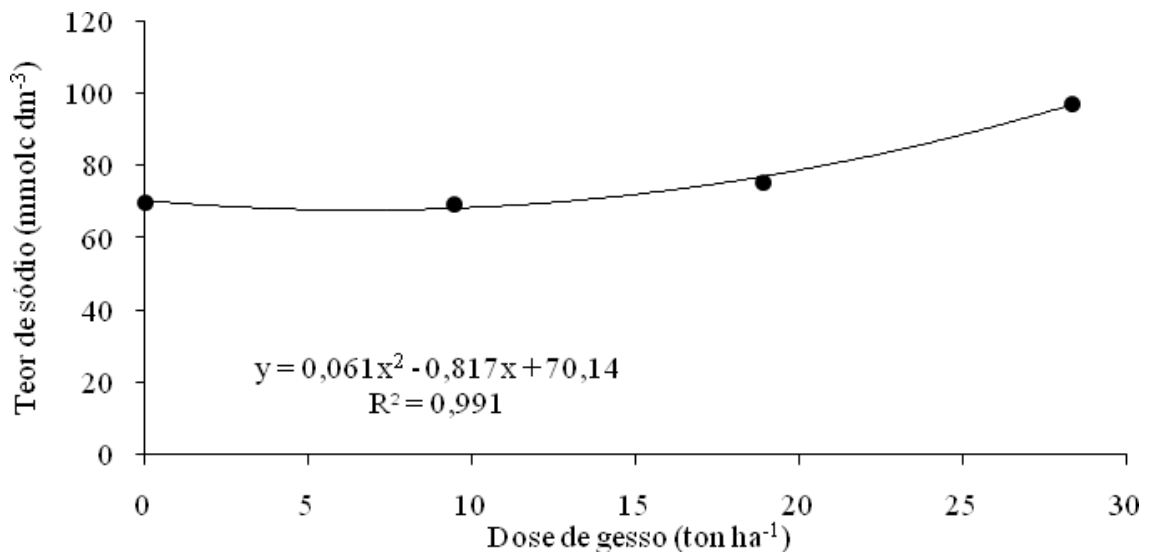

Figura 5. Teores de sódio do solo em função de diferentes doses de gesso aplicados. Campina Grande, PB, 2013. 